SUPPORTING INFORMATION

\title{
Can Costs of Pesticide Exposure for Bumblebees Be Balanced by Benefits from a Mass-Flowering Crop?
}

\author{
Maj Rundlöf $f^{a *} \&$ Ola Lundin ${ }^{\mathrm{b}}$ \\ ${ }^{a}$ Lund University, Department of Biology, SE-223 62 Lund, Sweden \\ ${ }^{\mathrm{b}}$ Swedish University of Agricultural Sciences, Department of Ecology, SE-750 07, Uppsala, \\ Sweden \\ *Corresponding author: \\ address: Lund University, Department of Biology, SE-223 62 Lund, Sweden \\ phone number: +46-46-2229561 \\ fax number: +46-46-222 4206 \\ email address: maj.rundlof@biol.lu.se
}

\section{This file contains:}

Supplementary Methods on (1) study design, (2) colony growth and reproduction in relation to clover field size, (3) effect of thiacloprid treatment on pest abundance and (4) additional analyses of bumblebee crop visitation in relation to pesticide treatment.

Table S1-S6

Figure S1-S2 


\section{SUPPLEMENTARY METHODS}

\section{Study design}

Bumblebee colonies were placed in three landscape types with either conventional red clover fields treated with the neonicotinoid thiacloprid $(n=6)$, untreated organic red clover fields $(n$ $=6$ ) or landscapes lacking clover fields ( $n=6$, figure 1 , table $S 1$ ). Landscape centres were 5.2-24.9 km apart within triplets, and no landscape centre was closer than $3.7 \mathrm{~km}$ to any other landscape centre (figure 1). Apart from the contrast in insecticide use, crop management is similar between conventionally and organically managed red clover grown for seed in Sweden ${ }^{1,2}$. Conventional farmers use herbicides to control weeds, but no fungicides, whereas organic farmers do not use any pesticides and to a larger extent rely on trimming or cutting the crop in spring for weed control. Clover fields were on average 13.8 ha (range 9.3-23.5 ha).

Organic clover fields were on average 4 ha larger than the conventional (table S3). Clover field size was, however, not related to bumblebee colony performance (table S6). Proportions of annual crops, other MFC and semi-natural grassland did not differ between landscape types, but there was a difference in proportion agricultural land (table S3). Landscapes with organic clover had less agricultural land than both landscapes with conventional clover $\left(\mathrm{F}_{1,10}\right.$ $=10.04, \mathrm{P}=0.0099)$ and landscapes without clover $\left(\mathrm{F}_{1,10}=11.53, \mathrm{P}=0.0068\right)$, while there was no difference between the latter two $\left(F_{1,10}=0.06, P=0.81\right)$ (table S3). The nonagricultural land consisted mainly of forest and urban land, of which forest was more abundant in landscapes with organic clover while urban land did not differ among landscape types (table S3). This fit the general pattern that organically managed farms are located in more extensively farmed areas with less agricultural land ${ }^{3,4}$. The low number of organically managed clover fields available in the region and their specific location were limitations in the design of the study. We handled this by including the proportion agricultural land as a covariate in all analysis of bumblebee colony performance (see Statistical analyses section in the article).

\section{Colony growth and reproduction in relation to clover field size}

Because the size of the focal clover field differed between organically and conventionally managed fields (table S3), we explored the relationship between clover field size and bumblebee colony weight change since placement in the field and reproduction in the form of number of new queens and males using the same models as in the main text but only including data from colonies in landscapes that were centered on clover fields. In summary, the model included proportion agricultural land in the landscape and landscape type (conventionally or organically managed clover) as explanatory variables and for colony weight also survey round and the interaction between survey round and landscape type. Neither colony weight change nor queen or male production were related to area of the focal red clover field (table S6).

\section{Effect of thiacloprid treatment on insect pests}

To determine how thiacloprid treatment affected the main crop pests, we measured the abundance of Protapion spp. weevils in insecticide treated and untreated plots in 19 red clover seed field 2011 and 2013. One field in 2011 was excluded, because we suspected thiacloprid was not properly applied as the insect pest density in this field was $37 \%$ higher in the plot assigned to receive thiacloprid treatment compared to in the untreated plot, whereas all other 
19 fields treated with thiacloprid had at least $72 \%$ fewer pests (on average 93\% fewer pests) (see figure $\mathrm{S} 1$ ).

Eighty (2013) to 120 (2011) red clover inflorescences, at the morphological stage where all individual flowers had recently withered, were picked from each of the two plots in each field for rearing of the weevils. The collected inflorescences were put in cardboard containers which were left in the laboratory for insects to emerge. We identified and counted the number of emerged Protapion spp. weevils in each sample. The number of weevils were summed per plot in each field prior to analyses. Data were analysed in a generalised linear mixed model with treatment (thiacloprid treated or untreated) and year (2011 or 2013) as explanatory variables, and field identity as a random variable. We assumed Poisson error distribution and $\log$ link, and the ln-transformed number of inflorescences collected per plot was included as an offset. We corrected for overdispersion using an extra model parameter (random _residual_).

The numbers of Protapion spp. seed weevils per inflorescence were lower in thiacloprid treated compared to untreated plots $\left(\mathrm{F}_{1,16}=64.54, \mathrm{P}<0.0010\right.$, figure $\left.\mathrm{S} 1\right)$ and higher in 2011 (mean $(95 \%$ confidence limits) $0.38(0.26-0.56))$ compared to $2013(0.18(0.11-0.31))\left(\mathrm{F}_{1,26}=\right.$ 9.35, $\mathrm{P}=0.0051)$.

\section{Additional analysis of bumblebee crop flower visitation}

To determine if additional pyrethroid applications in some fields that were treated with thiacloprid affected bumblebee crop flower visitation rates, we specified a generalised linear mixed model with type of insecticide treatment (untreated, treated only with thiacloprid or treated both with thiacloprid and a pyrethroid) as an explanatory variable. All other aspects of the model were kept as in the original model (see main text). In summary, year (2011 or 2013) and crop inflorescence density were explanatory variables and field identity was a random variable. The estimate and contrast options were used to explore the differences in bee densities between insecticide treatments.

This additional analysis revealed that the higher bumblebee visitation in insecticide treated compared to untreated plots were driven by higher numbers of bumblebees in plots treated only with thiacloprid compared to control plots $\left(\mathrm{F}_{1,33}=5.82, \mathrm{P}=0.022\right)$, whereas bumblebee visitation in plots that received a pyrethroid application in addition to the thiacloprid did not differ from bumblebee visitation in either thiacloprid treated $\left(\mathrm{F}_{1,33}=1.26, \mathrm{P}=0.27\right)$ or untreated plots $\left(\mathrm{F}_{1,33}=0.57, \mathrm{P}=0.46\right)$, figure $\left.\mathrm{S} 2\right)$. Other results remained qualitatively the same as in the main analysis. That is, bee visitation was higher in 2011 compared to 2013 and increased with higher crop bloom densities, and crop bloom was not affected by either the type of insecticide treatment or year (table S5).

\section{SUPPLEMENTARY REFERENCES}

1. Swedish Seed and Oilseed Growers Organisation. Rödklöver - odlingsvägledning. Swedish Seed and Oilseed Growers Organisation: Alnarp, 2018.

2. Swedish Board of Agriculture. Rödklöver - odlingsråd vid ekologisk fröodling. Swedish Board of Agriculture: Jönköping, 2010. 
3. Rundlöf, M.; Smith, H. G., The effect of organic farming on butterfly diversity depends on landscape context. Journal of Applied Ecology 2006, 43, (6), 1121-1127.

4. Gabriel, D.; Carver, S. J.; Durham, H.; Kunin, W. E.; Palmer, R. C.; Sait, S. M.; Stagl, S.; Benton, T. G., The spatial aggregation of organic farming in England and its underlying environmental correlates. Journal of Applied Ecology 2009, 46, (2), 323-333. 


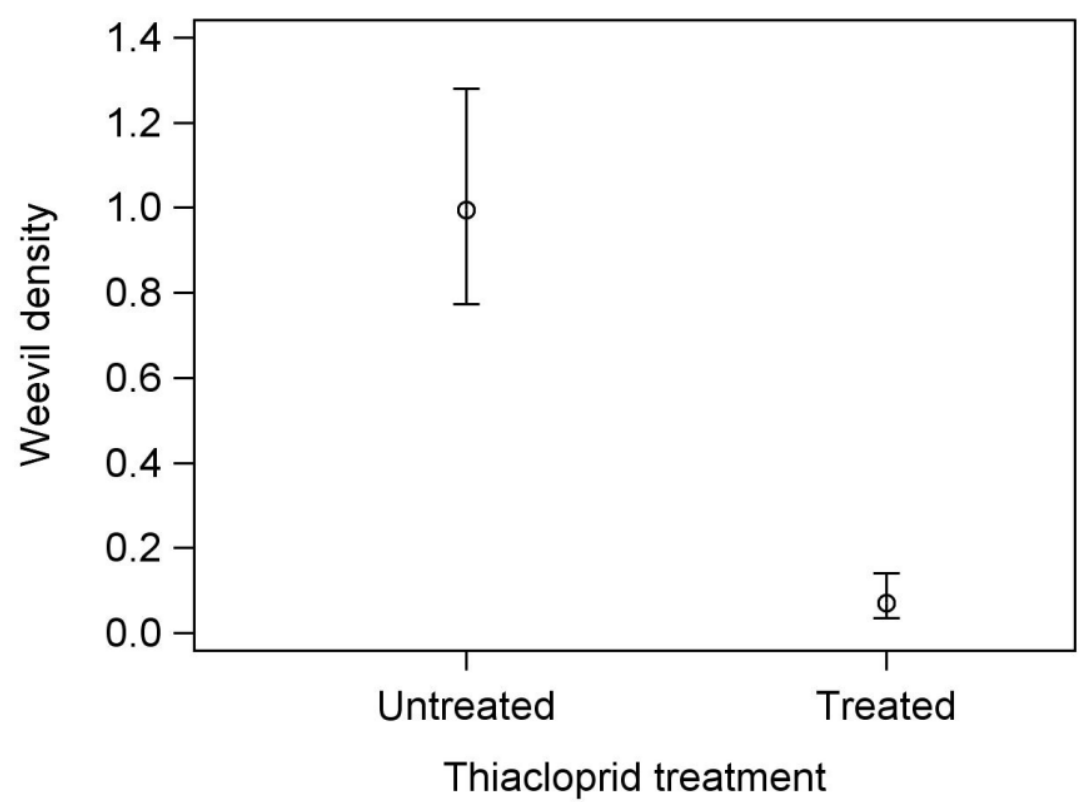

Figure S1. Mean ( $\pm 95 \%$ confidence limits) densities of Protapion spp. seed weevils (individuals per inflorescence) in 38 plots in 19 red clover seed fields in relation to thiacloprid treatment. Each of the 19 fields had one untreated and one treated plot. Means and confidence limits are based on model estimated least square means, back-transformed using the ILINK option. 


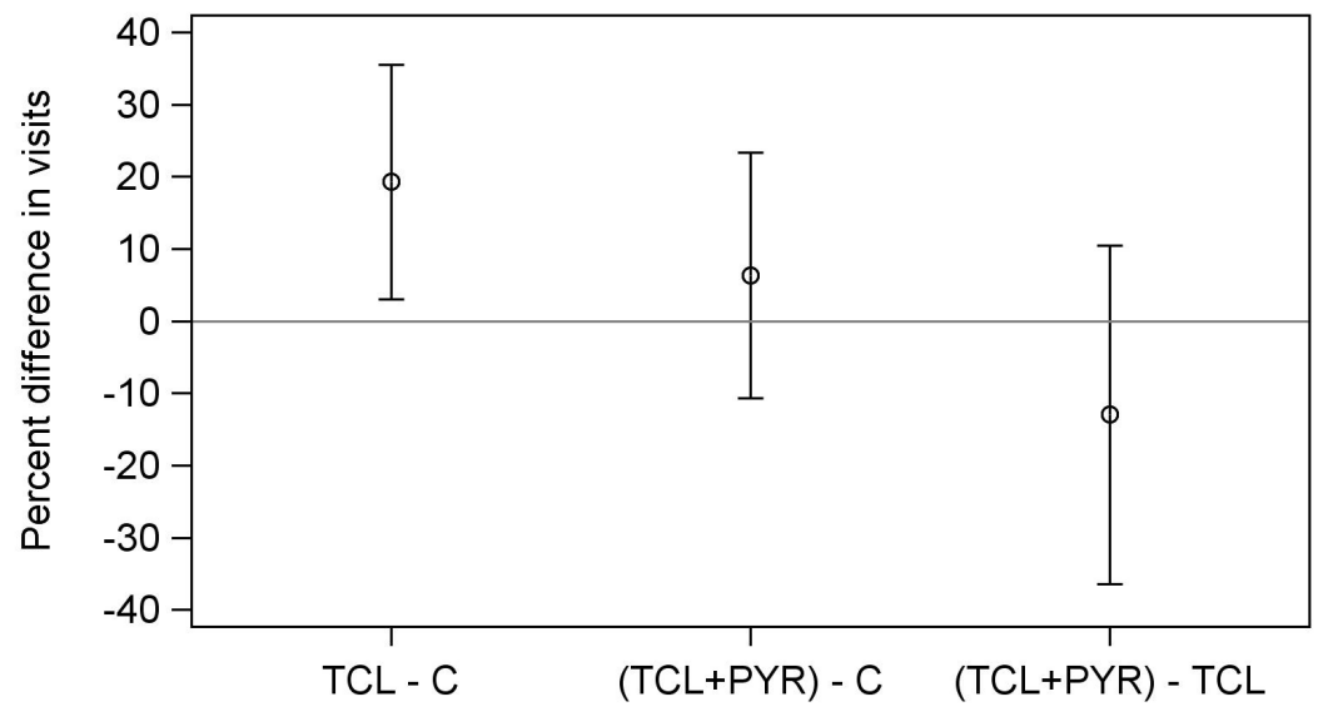

Figure S2. Pairwise comparisons of percent difference in bumblebee crop flower visitation between thiacloprid (TCL, $n=7$ ), thiacloprid and pyrethroid treated (TCL+PYR, $n=12$ ) and untreated control plots $(\mathrm{C}, \mathrm{n}=19)$ in 19 red clover seed fields. Means and 95\% confidence limits for each treatment are presented in table S5. 
Table S1. Dates of placement and weighing of bumble bee colonies as well as dates of thiacloprid application at the conventionally managed red clover seed fields in 2015 .

\begin{tabular}{|c|c|c|c|c|c|c|}
\hline Triplet & Landscape type & Placement & $\begin{array}{c}\text { Weighing } \\
1\end{array}$ & $\begin{array}{l}\text { Weighing } \\
2\end{array}$ & $\begin{array}{l}\text { Weighing } \\
3\end{array}$ & $\begin{array}{l}\text { Thiacloprid } \\
\text { application }\end{array}$ \\
\hline 1 & Organic clover & June 17 & July 7 & July 20 & August 4 & \\
\hline 1 & Conv. clover & June 17 & July 7 & July 20 & August 4 & July 1 \\
\hline 1 & Control & June 17 & July 7 & July 20 & August 4 & \\
\hline 2 & Organic clover & June 17 & July 8 & July 22 & August 6 & \\
\hline 2 & Conv. clover & June 17 & July 8 & July 22 & August 6 & July 7 \\
\hline 2 & Control & June 17 & July 8 & July 22 & August 6 & \\
\hline 3 & Organic clover & June 17 & July 12 & July 24 & July 29 & \\
\hline 3 & Conv. clover & June 17 & July 12 & July 24 & July 29 & July 18 \\
\hline 3 & Control & June 17 & July 12 & July 24 & July 29 & \\
\hline 4 & Organic clover & June 18 & July 13 & July 27 & August 4 & \\
\hline 4 & Conv. clover & June 18 & July 13 & July 27 & August 4 & $\begin{array}{l}\text { June } 25 \\
\text { and July } 16\end{array}$ \\
\hline 4 & Control & June 18 & July 13 & July 27 & August 4 & \\
\hline 5 & Organic clover & June 18 & July 3 & July 16 & August 3 & \\
\hline 5 & Conv. clover & June 18 & July 3 & July 16 & August 3 & July 7 \\
\hline 5 & Control & June 18 & July 3 & July 16 & August 3 & \\
\hline 6 & Organic clover & June 18 & July 6 & July 23 & July 29 & \\
\hline 6 & Conv. clover & June 18 & July 6 & July 23 & July 29 & $\begin{array}{l}\text { June } 9 \text { and } \\
\text { July } 7\end{array}$ \\
\hline 6 & Control & June 18 & July 6 & July 23 & July 29 & \\
\hline
\end{tabular}


Table S2. Insecticide treatments details for red clover fields where we compared bumblebee densities between insecticide treated and untreated plots 2011 and 2013, and for conventionally managed fields in 2015. For each field, the active ingredient for the first (AI 1) and second (AI 2) insecticide treatments as well as the dose applied and application date are presented. All doses are expressed as gram active ingredient applied per hectare.

\begin{tabular}{|c|c|c|c|c|c|c|c|}
\hline Year & Field & AI 1 & Dose 1 & Date 1 & $\mathrm{AI} 2$ & Dose 2 & Date 2 \\
\hline$\overline{2011}$ & 1 & $\alpha$-cypermethrin & 20 & June 21 & thiacloprid & 72 & June 29 \\
\hline 2011 & 2 & thiacloprid & 72 & June 25 & - & - & - \\
\hline 2011 & 3 & $\tau$-fluvalinate & 48 & June 13 & thiacloprid & 72 & June 27 \\
\hline 2011 & 4 & thiacloprid & 72 & June 20 & $\tau$-fluvalinate & 60 & July 7 \\
\hline 2011 & 5 & esfenvalerate & 15 & June 26 & thiacloprid & 72 & July 5 \\
\hline 2011 & 6 & $\tau$-fluvalinate & 72 & June 20 & thiacloprid & 72 & July 5 \\
\hline 2011 & 7 & $\tau$-fluvalinate & 72 & June 16 & thiacloprid & 72 & July 9 \\
\hline 2011 & 8 & thiacloprid & 72 & June 29 & - & - & - \\
\hline 2011 & 9 & thiacloprid & 60 & June 26 & $\tau$-fluvalinate & 60 & July 4 \\
\hline 2011 & 10 & thiacloprid & 72 & June 26 & - & - & - \\
\hline 2011 & 11 & thiacloprid & 72 & June 26 & - & - & - \\
\hline 2013 & 12 & $\beta$-cyfluthrin & 10 & June 18 & thiacloprid & 72 & July 4 \\
\hline 2013 & 13 & $\lambda$-cyhalothrin & 13.75 & June 24 & thiacloprid & 72 & July 2 \\
\hline 2013 & 14 & thiacloprid & 72 & July 7 & - & - & - \\
\hline 2013 & 15 & thiacloprid & 72 & June 20 & - & - & - \\
\hline 2013 & 16 & $\tau$-fluvalinate & 72 & June 18 & thiacloprid & 72 & July 2 \\
\hline 2013 & 17 & $\alpha$-cypermethrin & 15 & June 24 & thiacloprid & 72 & July 5 \\
\hline 2013 & 18 & thiacloprid & 72 & July 5 & - & - & - \\
\hline 2013 & 19 & $\tau$-fluvalinate & 60 & June 23 & thiacloprid & 72 & July 8 \\
\hline 2015 & 20 & thiacloprid & 72 & July 1 & - & - & - \\
\hline 2015 & 21 & thiacloprid & 72 & July 7 & - & - & - \\
\hline 2015 & 22 & $\tau$-fluvalinate & 48 & July 11 & thiacloprid & 72 & July 18 \\
\hline 2015 & 23 & thiacloprid & 72 & June 25 & thiacloprid & 72 & July 16 \\
\hline 2015 & 24 & thiacloprid & 120 & July 7 & - & - & - \\
\hline 2015 & $25^{1}$ & thiacloprid & 72 & June 9 & thiacloprid & 72 & July 7 \\
\hline
\end{tabular}

${ }^{1}$ Insecticide use also included an early treatment with $\tau$-fluvalinate $72 \mathrm{~g} \mathrm{ha}^{-1}$ on June 5. 
Table S3. Focal clover field size, proportion of agricultural land, forest and urban land in the landscape and proportion annual crops, other mass-flowering crops ${ }^{1}$ (MFC) and semi-natural grassland of the agricultural land in the landscapes surrounding the bumblebee colonies and the initial colony weight and number of workers when colonies were placed in the landscapes in relation to landscapes types (control without clover, conventional clover, organic clover). Means and confidence limits (cl) are based on model estimated least square means, backtransformed using the ILINK option when needed.

\begin{tabular}{|c|c|c|c|c|c|}
\hline & \multicolumn{2}{|c|}{ Landscape type } & \multicolumn{3}{|c|}{ Estimate (mean $(95 \% \mathrm{cl})$ ) } \\
\hline & $\mathrm{F}_{\mathrm{df}}$ & $\mathrm{P}$ & $\begin{array}{l}\text { Control without } \\
\text { clover }\end{array}$ & $\begin{array}{c}\text { Conventional } \\
\text { clover }\end{array}$ & $\begin{array}{l}\text { Organic } \\
\text { clover }\end{array}$ \\
\hline $\begin{array}{l}\text { Focal clover } \\
\text { field size (ha) }\end{array}$ & $\begin{array}{l}45.47_{1}, \\
5\end{array}$ & 0.0011 & & $11.8(7.7-15.9)$ & $15.8(11.7-19.9)$ \\
\hline $\begin{array}{l}\text { Agricultural } \\
\text { land }\end{array}$ & $7.49_{2,10}$ & 0.010 & $0.75(0.62-0.85)$ & $0.74(0.60-0.84)$ & $0.55(0.40-0.69)$ \\
\hline Annual crops & $0.65_{2,10}$ & 0.65 & $0.74(0.56-0.86)$ & $0.81(0.65-0.91)$ & $0.72(0.52-0.86)$ \\
\hline Other $\mathrm{MFC}^{1}$ & $0.10_{2,10}$ & 0.90 & $0.15(0.10-0.21)$ & $0.15(0.10-0.21)$ & $0.13(0.081-0.21)$ \\
\hline $\begin{array}{l}\text { Semi-natural } \\
\text { grassland }\end{array}$ & $0.10_{2,11}$ & 0.91 & $\begin{array}{l}0.040(0.014- \\
0.11)\end{array}$ & $\begin{array}{l}0.039(0.014- \\
0.11)\end{array}$ & $\begin{array}{l}0.047(0.017- \\
0.13)\end{array}$ \\
\hline Forest & $\begin{array}{l}10.39_{2} \\
9\end{array}$ & 0.0041 & $\begin{array}{l}0.039(0.012- \\
0.12)\end{array}$ & $\begin{array}{l}0.045(0.015- \\
0.13)\end{array}$ & $0.19(0.074-0.39)$ \\
\hline Urban & $1.76_{2,15}$ & 0.21 & $\begin{array}{l}0.015(0.0035- \\
0.066)\end{array}$ & $\begin{array}{l}0.030(0.010- \\
0.083)\end{array}$ & $\begin{array}{l}0.059(0.028- \\
0.12)\end{array}$ \\
\hline $\begin{array}{l}\text { Initial colony } \\
\text { weight }(\mathrm{g})\end{array}$ & $1.03_{2,15}$ & 0.38 & $130(103-157)$ & $125(98.4-152)$ & $106(79.1-133)$ \\
\hline $\begin{array}{l}\text { Initial worker } \\
\text { number }\end{array}$ & $0.28_{2,15}$ & 0.76 & $87.9(78.1-98.2)$ & $91.7(81.8-103)$ & $92.3(82.4-103)$ \\
\hline
\end{tabular}

${ }^{1}$ Other mass-flowering crops included autumn-sown oilseed rape (66\%), canning peas (13\%), spring-sown oilseed rape $(10 \%)$, field beans $(7 \%)$ and the remaining were spring and autumn-sown turnip rape, herbs and vegetable seed, fruit orchard, strawberry and other berries, linseed and sunflower. 
Table S4. Bumblebee abundances in the clover fields, with cuckoo bumblebee species listed separately at the bottom.

\begin{tabular}{ll}
\hline Species & $\mathrm{N}$ individuals \\
\hline Bombus hortorum & 28 \\
Bombus hypnorum & 2 \\
Bombus lapidarius & 134 \\
Bombus muscorum & 12 \\
Bombus pascuorum & 17 \\
Bombus pratorum & 2 \\
Bombus ruderarius & 10 \\
Bombus soroëensis & 1 \\
Bombus subterraneus & 31 \\
Bombus sylvarum & 27 \\
Bombus terrestris agg. & 839 \\
Bombus spp. & 97 \\
Bombus bohemicus & 1 \\
Bombus rupestris & 3 \\
Bombus vestalis & 2 \\
\hline
\end{tabular}


Table S5. Bumblebee crop flower visitation (individuals per 50 by $1 \mathrm{~m}$ transect) and crop bloom density (number of clover inflorescences with at least five open flowers per $0.25 \mathrm{~m}^{2}$ ) in relation to treatment (Untreated - no insecticide treatment, TCL - treated with only thiacloprid, TCL + PYR - treated with thiacloprid and a pyrethroid) and year. Estimates are means $( \pm 95 \%$ confidence limits) based on model estimated least square means, backtransformed using the ILINK option when needed, and the model-estimated slope (with standard error within parenthesis) for the continuous variable crop bloom.

\begin{tabular}{llllllll}
\hline & & \multicolumn{3}{c}{ Bumblebee visitation } & \multicolumn{3}{l}{ Crop bloom density } \\
& Categories & $\mathrm{F}_{\mathrm{df}}$ & $\mathrm{P}$ & Estimate & $\mathrm{F}_{\mathrm{df}}$ & $\mathrm{P}$ & Estimate \\
\hline Treatment & Untreated & $3.39_{2,33}$ & 0.046 & $6.3(4.1-9.6)$ & $0.10_{2,21}$ & 0.90 & $52(46-58)$ \\
& TCL & & & $7.6(4.9-12)$ & & & $54(45-62)$ \\
& TCL + PYR & & & $6.7(4.4-10)$ & & $52(45-59)$ \\
Year & 2011 & $9.37_{1,14}$ & 0.0084 & $12(7.3-21)$ & $<0.01_{1,17}>0.99$ & $52(45-59)$ \\
& 2013 & & & $3.8(2.0-7.2)$ & & & $52(44-61)$ \\
Crop bloom & & $6.45_{1,33}$ & 0.016 & $0.013(0.0050)$ & & \\
\hline
\end{tabular}


Table S6. Bumblebee colony weight change from placement in the field and total production of new queens and males, only for landscapes with clover fields, in relation to proportion agricultural land in the landscape, area of the focal clover field and landscape type (conventional thiacloprid-treated clover, organic untreated clover) and for colony weight also survey round and the interaction between survey round and landscape type.

\begin{tabular}{lllllll}
\hline & \multicolumn{2}{l}{$\begin{array}{l}\text { Colony weight } \\
\text { change }(\mathrm{g})\end{array}$} & Queens & & \multicolumn{2}{l}{ Males } \\
& $\mathrm{F}_{\mathrm{df}}$ & $\mathrm{P}$ & $\mathrm{F}_{\mathrm{df}}$ & $\mathrm{P}$ & $\mathrm{F}_{\mathrm{df}}$ & $\mathrm{P}$ \\
\hline $\begin{array}{l}\text { Proportion } \\
\text { agricultural land }\end{array}$ & $0.05_{1,8}$ & 0.82 & $0.29_{1,8}$ & 0.61 & $1.31_{1,8}$ & 0.29 \\
Area clover (ha) & $3.40_{1,8}$ & 0.10 & $1.52_{1,7}$ & 0.26 & $2.34_{1,8}$ & 0.17 \\
Landscape type & $0.77_{1,8}$ & 0.41 & $0.27_{1,8}$ & 0.62 & $0.23_{1,8}$ & 0.65 \\
Round & $21.20_{2,47}<0.0010$ & & & & \\
Type x Round & $2.41_{2,47}$ & 0.10 & & & & \\
\hline
\end{tabular}

